\title{
¿Por qué es difícil subordinar la medicina tradicional andina a la biomedicina?
}

\author{
Why is it hard to subordinate traditional Andean \\ medicine to biomedicine?
}

\author{
Carmen Beatriz Loza \\ Diretora de pesquisa/Instituto Boliviano de Medicina Tradicional Kallawaya. \\ cbloza@gmail.com
}

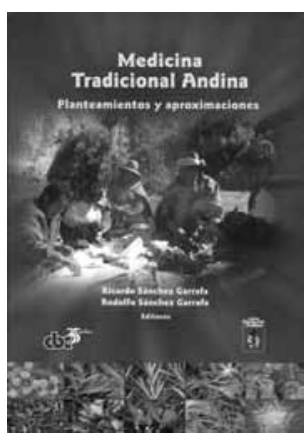

SÁNCHEZ GARRAFA, Ricardo; SÁNCHEZ Medicina tradicional andina: planteamientos y aproximaciones. Cusco: Centro Bartolomé de Las Casas; Centro de Medicina Andina, 2009. 409p. GARRAFA, Rodolfo (Ed.).

1 ste libro reúne 24 textos relacionados con la medicina tradicional Candina, seguidos de un conjunto de paratextos compuestos por el colofón sobre el $25^{\circ}$ aniversario del Centro de Medicina Andina del Cusco y cuatro anexos. A partir de ese conjunto, los editores peruanos, el antropólogo Rodolfo Sánchez Garrafa y el químico Ricardo Sánchez Garrafa, desean mostrar la "relación existente y posible entre la medicina tradicional y la medicina académica", siguiendo el ansiado proyecto global para las Américas impulsado por la Organización Mundial de la Salud (OMS) y la Organización Panamericana de la Salud (OPS), implantado desde la segunda mitad del siglo $\mathrm{XX}$ y vigente hasta la actualidad. De partida, recupera textos dispersos, escritos entre 1922 y 2006, poniéndolos al alcance del lector. El 50\% por ciento proviene de una diversidad de libros extranjeros o peruanos, seguido de un $33 \%$ por ciento de textos redactados, al parecer para el volumen, quedando un $17 \%$ restante de artículos tomados de revistas o de comunicaciones internacionales especializadas. Un 63\% por ciento de todo ese material fue redactado por autores peruanos y un $37 \%$ por ciento por autores europeos y norteamericanos. Ese cuerpo reflexivo heterogéneo ofrece una visión panorámica en cuatro partes distintas y complementarias: las nociones introductorias al estudio de la medicina tradicional; los diagnósticos y las terapias de los especialistas; la articulación de la medicina tradicional y académica en los sistemas formales de salud y, finalmente, la significación de la medicina tradicional para los organismos reguladores de la salud. Sin lugar a dudas, todas esas problemáticas son claves y actualmente clásicas, pues permiten entender el marco que debe ser tomado en cuenta para el análisis de una articulación de la medicina tradicional con la biomedicina de Los Andes. Sin embargo, hay más, pues el libro presenta una gama de temáticas que han preocupado a los antropólogos y biomédicos a lo largo del siglo XX. Por ejemplo, varios autores alertan acerca de la falta de uniformidad

http://dx.doi.org/10.1590/S0104-59702014000100008 
conceptual al emplear categorías muy diversas para denominar a la "otredad médica", llamada de manera equivalente medicina folclórica, popular, naturista, indígena, natural o tradicional (p.19-27). La falta de consenso y el uso indiscriminado de categorías disímiles se mantiene como un problema absolutamente vigente no solo entre los propios terapeutas, que alguna vez emplearon de manera intercambiable estas categorías para legitimar su practica, sino también por los pacientes y hasta los especialistas que en épocas pasadas no dieron la importancia necesaria a las definiciones conceptuales y sus significados. Pero, resulta que si bien la terminología utilizada es problemática, muchos autores, particularmente biomédicos, habrían enfatizado en averiguaciones acerca de la etiología de las enfermedades identificadas por los indígenas y la población popular, razón por la cual elaboraron listas con causales explicativas para entenderlas. Una clara ilustración de esa tendencia es el texto de David Frisancho Pineda (p.111-128). Asimismo, la reiteración de que la teoría médica tradicional es distinta de la biomédica genera una literatura que enfatiza la labor de traducción terminológica, establece equivalencias y parecidos entre ambas medicinas (p.119-128). En suma, el corpus permite comprender que, en distintos periodos, quienes se ocuparon de estudiar la medicina tradicional relegaron las voces de los terapeutas y de sus pacientes. Mientras que en otros períodos la situación cambia de manera contrastante, incorporando no sólo aquellas voces sino visibilizando las representaciones que ellos tienen de la enfermedad, la salud y la curación (p.77-96; 143-163; 199-214).

Los cuatro textos que conforman los anexos tienen un valor histórico incuestionable. Así, el documento del 25ㅇ aniversario del Centro de Medicina Andina del Cusco presenta un balance interesante, puesto que condensa su experiencia desde su creación, cuando se perseguía y menospreciaba a las medicinas tradicionales, hasta el presente en que se ha llegado a reconocer la existencia de diversos sistemas médicos en muchos de los países andinos. Un proceso que recorrió el Centro de Medicina Andina en sus diversas fases y realizó ajustes en las concepciones, en los fines y los medios para proseguir una labor encaminada decididamente a “...buscar la complementariedad de los diferentes sistemas médicos para que estos sirvan efectivamente al complejísimo ser humano que no puede ser entendido ni diagnosticado ni tratado completamente por una sola corriente [médica]" (p.375-384). Ese proyecto encontró sus fundamentos en la famosa "Declaración de Alma-Ata" del 12 de septiembre de 1978. Le siguen en los anexos los "Puntos clave: estrategia de la OMS sobre medicina tradicional 2002-2005", donde se presenta una definición de la medicina tradicional y se aclaran los alcances, ofreciendo sobre todo las tácticas que desarrollarían a corto plazo. Esto se puede apreciar con los documentos siguientes que tratan de la medicina tradicional estándar en un contexto mundial y donde se expone la política global normativa (p.391-409). Los anexos entran en diálogo directo, por ejemplo, con el texto del médico Manuel Fernández Ibarguen acerca de "la OMS y los sistemas médicos tradicionales" (p.325-337) y con el del antropólogo español Gerardo Fernández Juárez quien, desde España, se empeña en dar sugerencias para implementar la interculturalidad en salud en Bolivia (p.273-290). En otros casos, los anexos no dialogan explícita y directamente con aquellas concepciones sobre enfermedad que vehiculan los entrevistados de la antropóloga argentina Carmen Muñoz Bernard (p.143-163). En efecto, esto sugeriría que la definición sobre medicina tradicional de la OMS no es la única, pues la gente tiene sus propias representaciones y sus propias formas de explicar la particularidad y 
riqueza de la medicina tradicional que durante siglos ha servido como un recurso importante, accesible y culturalmente apto en Los Andes.

El libro cumple con alguna dificultad su objetivo porque no evidencia del todo la articulación de la biomedicina y las medicinas tradicionales andinas. Subrayemos que son limitadas las muestras concretas de los mecanismos de "complementariedad" médica, a pesar de los anhelos de la OMS/OPS y los despliegues de sus estrategias, respaldadas con significativas inversiones económicas. De ahí que, actualmente, nos encontramos en la necesidad de conocer los mecanismos, las respuestas y, consecuentemente, los resultados de ese proceso. Para el mundo andino se necesita un balance imparcial acerca de la salud intercultural. Hasta el presente han dominado narrativas que han publicitado las acciones ministeriales privilegiando la voz oficial de los decidores políticos, restando valor a la voz de los terapeutas tradicionales que tienen su propia visión acerca de los efectos de la interculturalidad funcional del sistema biomédico hegemónico (Campos Navarro, 2006, p.373-388). Así mismo, han dominado las narrativas triunfalistas de un avance considerable y consensuado en la implementación de salud intercultural neoliberal, sin mostrar el lado problemático de la institucionalización para las medicinas tradicionales, simplemente elogiando el cumplimiento de las metas de las agencias de cooperación internacional. Esos vacíos en la investigación se desprenden tanto en la obra reseñada como en las publicaciones compiladas por Gerardo Fernández Juárez para América Latina $(2004,2006)$. Esas narrativas han dejado de lado los debates acerca del propio concepto de interculturalidad - sea como herramienta de emancipación o como vehículo hacia un neocolonialismo global - y sus múltiples definiciones con matices propios (Walsh, 2009).

Con todo, la fortaleza del libro radica en la estupenda selección de textos que nos permite constatar maneras diferenciadas para acercarse a un mismo objeto de estudio en el siglo XX. Pero, nótese también que el aporte consiste en haber probado que los estudios y reflexiones acerca de la medicina tradicional no se originaron desde la antropología del norte, sino como fruto de la investigación de los biomédicos en el Perú. Se trataría, entonces, de un esfuerzo formidable que respondería a diversas motivaciones y no necesariamente a las influencias de la OMS/OPS. En el libro están las garantías, quedando claro que la producción del conocimiento no siempre se engendra en condiciones de dependencia y como respuesta a las demandas de los organismos internacionales.

Uno de los aspectos más notables del libro es constatar una diversidad de opiniones contradictorias acerca de la mentada complementariedad médica. Mientras algunos antropólogos y biomédicos secundan los esfuerzos de la OMS/OPS, otros de manera contundente, como Polia Meconi, consideran que es improbable la integración de ambas medicinas a pesar de todos los empeños. Más bien, la biomedicina en las últimas décadas "ha sido dirigida a la búsqueda de nuevos remedios fitoterapéuticos por parte de las multinacionales farmacéuticas más que al estudio y al conocimiento de las estructuras profundas de la medicina tradicional" (p.107). Planteamiento reforzado, en el mismo libro, por el biomédico Duncan Pedersen quien agrega: "Los esfuerzos de racionalización e integración de prácticas tradicionales en los sistemas oficiales de atención han sido escasos, de corta duración, casi siempre en la subordinación de la medicina tradicional al sistema oficial o en el empobrecimiento del efecto terapéutico y de la eficacia simbólica" (p.58). Ninguno de los 
autores de la compilación se refiere a la forma contraproducente de la institucionalización de las políticas de interculturalidad en salud, en las cuales el papel de los médicos tradicionales es simplemente funcional, decorativo o servil al proyecto hegemónico biomédico.

Más allá de esa tensión que produce, se quiera o no reconocer, el proyecto de interculturalidad en salud trae a colación un tema no menos importante y polémico: el papel del antropólogo ante ese tremendo proceso de cambio que se desarrolla en el contexto de un mundo global. Según Polia Meconi, la función del estudioso consistiría en estudiar, penetrar y comprender las medicinas tradicionales andinas para entregar el fruto de sus estudios a la historia universal. Una vez más, Polia Meconi se interroga acerca del porvenir de la medicina tradicional y también de las posibilidades existentes para su integración. Su respuesta es interesante porque considera que son las condiciones históricas y culturales las que en definitiva permitirán la articulación o no de los sistemas médicos, en vistas de la existencia de realidades muy contrastantes. Con esto, se confirma que, en el caso andino, las experiencias son realmente distintas de un país al otro, de un sistema médico tradicional al otro y, a pesar de ello, se pretende replicar experiencias, calcar estrategias y formular modelos comunes para lograr la articulación de las medicinas con el claro propósito de controlarlas. Aun así, "la medicina tradicional existirá hasta que exista una sociedad tradicional" (p.107). De tal suerte, deberemos volcar la mirada al acelerado proceso de modernización de la medicina tradicional institucionalizada que alienta la globalización y, en ese contexto, ver cuáles son las respuestas que plantean terapeutas y pacientes ante el proyecto de la interculturalidad en salud estatizada. La marginación extrema o el reacomodo de los terapeutas tradicionales son posibles y están ahora más cerca que nunca de suceder en Los Andes del siglo XXI.

\section{REFERENCIAS}

CAMPOS NAVARRO, Roberto.

Procesos de legalización e interculturalidad en las medicinas indígenas de México y Bolivia. In: Fernández Juárez, Gerardo (Coord.). Salud e interculturalidad en América Latina: antropología de la salud y crítica intercultural. Quito: AbyaYala. p.373-388. 2006.

FERNÁNDEZ JUÁREZ, Gerardo (Coord.). Salud e interculturalidad en América Latina: antropología de la salud y crítica intercultural. Quito: Abya-Yala. 2006.
FERNÁNDEZ JUÁREZ, Gerardo (Coord.). Salud e interculturalidad en América Latina: perspectivas antropológicas. Quito: Abya-Yala. 2004.

WALSH, Catherine. Interculturalidad crítica y educación intercultural. In: Viaña, Jorge; Walsh, Catherine; Tapia, Luis. Construyendo interculturalidad crítica. La Paz: Instituto Internacional de Integración Andres Bello. p.75-96. 2009. 